Yayınlayan: Ankara Üniversitesi KASAUM

Adres: Kadın Sorunları Araştırma ve Uygulama Merkezi, Cebeci 06590 Ankara

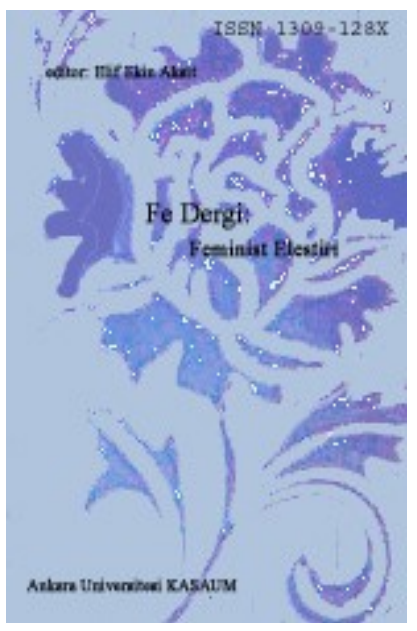

Fe Dergi: Feminist Eleștiri Cilt 5, Sayı 2

Erişim bilgileri, makale sunumu ve ayrıntılar için:

http://cins.ankara.edu.tr/

Olağanüstü Savaşın, Olağanlaşan Barışı: Kadınların

Gözünden Barış Süreci

Zehra Yllmaz

Çevrimiçi yayına başlama tarihi: 24 Aralık 2013

Bu makaleyi alıntılamak için: Zehra Yılmaz, "Olağanüstü Savaşın, Olağanlaşan Barışı: Kadınların Gözünden

Barış Süreci” Fe Dergi 5, no. 2 (2013), 53-58.

URL: http://cins.ankara.edu.tr/10_7.html

$\mathrm{Bu}$ eser akademik faaliyetlerde ve referans verilerek kullanılabilir. Hiçbir şekilde izin alınmaksızın çoğaltılamaz. 


\title{
Olağanüstü Savaşın, Olağanlaşan Barışı: Kadınların Gözünden Barış Süreci
} Zehra Yılmaz*

Kadınların savaştan nasıl zarar gördüğü, bu zararın nasıl telafi edilebileceği ve kadınları da içeren bir barışın nasıl tesis edilebileceği tartışılmaktadır. Çıkışsız görünen savaş sarmalından tek bir formülle çıkmak mümkün görünmezken barışı olağanlaştırmanın en mümkün yolu daha çok biraraya gelip konuşmak, her boyutuyla barışı ele almak gibi görünüyor. Yani şimdilik barışı konuşmaya başlamanın kendisi oldukça somut bir eylem gibi duruyor. Elinizdeki bu söyleşi de 2004 yllından bu yana Van'da faaliyet gösteren Van Kadın Derneği'nden iki aktivist kadın olan Zozan Özgökçe ve Belde Bayındırli ile barışı konuşmak üzere yapılan öyle bir konuşma denemesi.

Anahtar Sözcükler: Barış, savaş, süreç, Kürt, kadın, Van.

\begin{abstract}
How can an Out of the Ordinary War Turn Into an Ordinary Peace: The Peace Process as Women see it

We have just started to discuss once again how war harms women, how this harm can be compensated and how a peace that includes women can be consolidated. For now, the most feasable option out of a spiral of war seems to be coming together and discussing peace more. In other words, talking about peace itself seems to be a concrete action for now. This interview, conducted with two activist women from Van Women's Association that has been formed in 2004, Zozan Özgökçe and Belde Bayındirli constitutes such an act.
\end{abstract}

Keywords: Peace, war, process, Kurdish, women, Van.

Giriş

Türkiye'de uzun süredir devam eden savaşın tarafları en sonunda barıştan sözetmeye başladı. Adını 'Barış Süreci' koydukları yeni dönem herkeste tedirgin bir bekleyişe neden oldu. Zira uzun süredir devam eden savaşın barış zamanı geldi. Ama sürecin yıkıcı ve yıpratıcı izlerinin aşılması karşılıklı duyulan güven sıkıntısı nedeniyle biraz zaman alacak gibi görünüyor. Taraflar barışmayan tarafın kim olacağı konusunda tedirgin. Tedirginliğin nedeni barıştan çekilen tarafın bu savaşın mağlubu olarak kabul edilecek olması. O nedenle her iki tarafta savaşı kazanabilmek için önce bu barışı kazanmak istiyor, bunda 1srar ediyor. Ama karşılıklı güven sıkıntısını bir türlü üzerinden atamıyor. Bu tedirginlik barışın ağır ve aksak ilerlemesine neden oluyor. Fakat hala savaşı kaybedecek olanın, emek isteyen, zaman isteyen barış için yeterince irade göstermeyen olacak olması süreçle ilgili bize umut veriyor.

Bu tedirgin bekleyiş sürerken, 2004 yılından bu yana Van'da faaliyet gösteren Van Kadın Derneği'nden iki aktivist kadınla barışı konuşmak üzere biraraya geldik. Zozan Özgökçe ve Belde Bayındırli ile yaptığımız görüşmede kadınların bu savaştan nasıl zarar gördüğünü, bu zararın nasıl telafi edilebileceğini ve kadınları da içeren bir barışın nasıl tesis edilebileceğini konuştuk. Kadınlarla deneyimlerini paylaştıkça bir kez daha gördüm ki savaş, uzun yıllar boyunca birçok boyutuyla insanların hayatını çıkışı olmayan bir sarmala sürüklemiş. Bugün de tek bir formülle bu sarmaldan çıkmak mümkün görünmüyor. Yıllarca süren olağanüstü savaşın, barışını olağanlaştırmak için daha çok biraraya gelip konuşmak, her boyutuyla barışı ele almak gerekiyor. Özellikle Kürt tarafının sıkça dile getirdiği 'soyut barışı artık somutlaştırmak gerek' itirazına belki ilk önemli katkıyı daha çok barış konuşmakla yapabiliriz. Şimdilik barışı konuşmaya başlamanın kendisi dahi oldukça somut bir eylem gibi duruyor. Elinizdeki bu söyleşi de öyle bir konuşma denemesi...

*Dr.,Van Yüzüncüyıl Üniversitesi, iỉBF, Uluslararası Illişkiler Bölümü. 


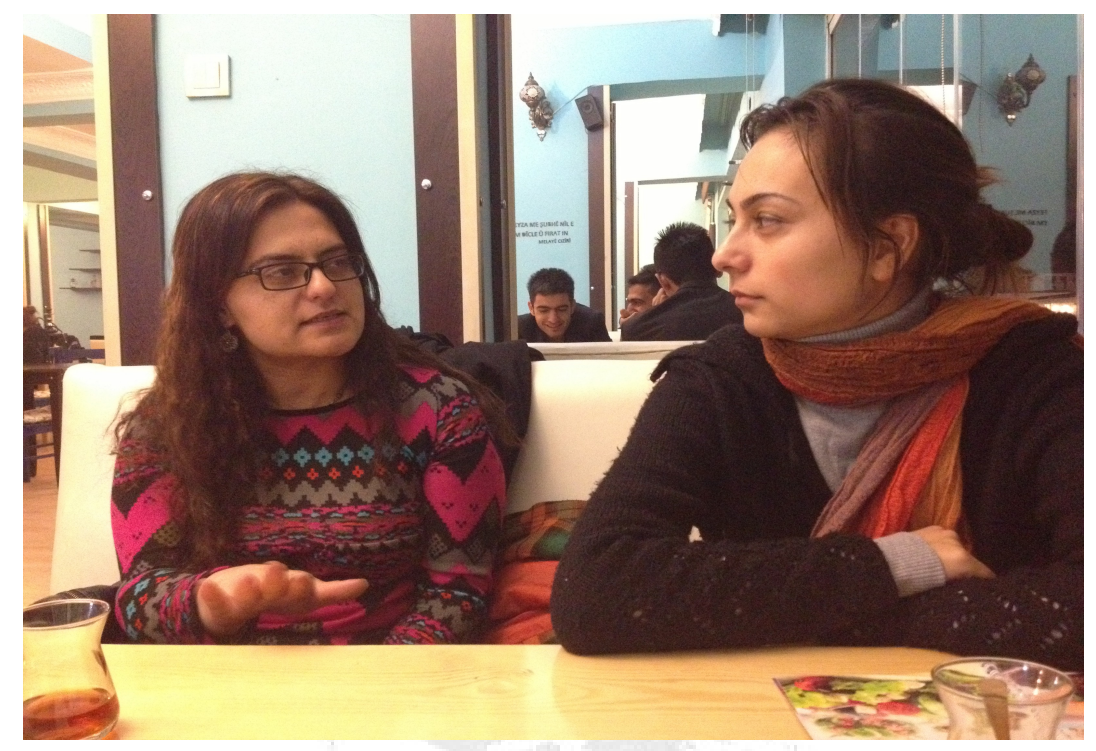

Ilk olarak niye biz şimdi barış konuşmaya başladık sorusuyla söyleşiye başlayalım. Hem zamanlama hem de muhatapları itibariyle değerlendirir misiniz? Ne değişti de barış zamanı geldi?

Zozan- Aslında biz yıllardır bunu konuşuyoruz.

Belde- Bu coğrafyada barışın hem özlemi, hem de nasıl olacağı, nasıl edileceğiyle ilgili hep konuşuluyordu. Hani bizim için bu yeni bir konuşma değil. Artık aslında bu konuşmalar bitmiş, onun yerine özlem ve artık olsa duygusu var bu topraklarda.

Peki bu topraklar için yeni değil ama Türkiye’nin bütünü için konuşursak, bu noktaya gelinmiş olmasının nedenleri neler olabilir?

Zozan- Çünkü artık biraz taraflarda bir bıkkınlık var. Savaşarak bir sonuca ulaşılamıyor şu durumda. Çünkü inat bir devlet de var bir yandan. Hala da asında bir barış süreci yok ama... Bir de ben mesela barış sürecinden şöyle bir şey anlamıyorum. Biz Türklerle PKK ile TSK barışacak, biz normalleşeceğiz diye bir şey yok elbette. Çünkü koskoca bir eğitim sistemi var, televizyonlardaki milliyetçilik var, aile kurumu... Bütün toplum olarak normalleşeceğiz diye bir şey yok. Yine biz Trabzon'a çekinerek gireceğiz, Sakarya’ya çekinerek gireceğiz, yine eylem yaparken eğer korkacaksak veyahut da Kürt dili tanınmayacaksa, Kürt kültürü tanınmayacaksa bunlar olmayacaksa bu barış demek değil ki. Şu anda olan süreç sadece sıcak savaşın bitmesi. Barış bizim için daha büyük bir ideal. Mesela benim için barış demek, buradaki halk hatta Türkiye'nin her yerinde hangi dil, kim kendisinin nasıl yönetilmesini istiyorsa öyle bir demokratik sistemin kurulması demektir. Benim için en barışçıl ortam budur. Yine şu şekilde, yine her yerde Türk bayağı, ne mutlu Türküm diyene, okullarda yine zapturapt eğitim sistemi, cinsiyetçi, milliyetçi, ırkçı eğitim sistemi olacaksa, bu bir barış ortamı değil ki benim için.

Peki siz kendi barışınızı nasıl tanımlarsınız?

Belde - Herkesin eşit, özgür, onurlu hissettiği bir ortam barış ortamı. Herkesin kendisini onurlu ve iyi hissettiği, kimsenin onursuz hissetmediği. Tabii bu onurlunun içerisinde aslında dil, kimlik falan var, cinsiyet de var, cinsel yönelim de var, fikirler de var, din-dinsizlik de var... Bunların hepsi var. Hatta aslında işin ekonomik boyutu da var onurlu hissetme kısmında. Çünkü fakirlik ya da yoksulluk da insanı çok iyi, onurlu hissettiren bir şey değil.

Barış öncelikle bir şiddetsiz halini gerektiriyor, değil mi? Örneğin şu anda PKK ve Türkiye tarafinda karşılıklı bir çatışmama hali var. Sizin şiddete yönelik bir eleştiriniz var mı?

Belde - Kişisel hikâyem şöyle; tam bir şiddetsizlik, yani şiddet karşıtı gibi hissediyordum kendimi; ama tabii şeyi filan da anlıyorum tabii Kürt hareketinin o şiddeti, son noktaya gelip işkencelerle şununla bununla artık başka bir yöne savrulması, 80'den sonra artık o dağ-gerilla hareketini de anlıyorum. Hani şey gibi gelmiyor 
bana, o da şiddet... Ama o şiddetin de yarattığı başka bir sarmal ve o militarist düzen devam ediyor gerçekten de. Orada hiç eleştirel olunmaması gibi bir durum yok, ama o biraz daha anlaşılır gibi geliyor bana. Hani devletin şiddetindense oradaki şiddeti ben anlıyorum. Ama dediğim gibi o da başka bir şeye sebebiyet veriyor. Yani o da militarizm, o da kadınla şey yapan başka bir sistemin parçası yani. Şiddeti devam ettiren şeyin parçası oluyor o da.

Sizce bu iki taraflı şiddet döneminden sonra Türkiye'de topluluklar tekrar birarada yaşayabilir mi? Bunun yarası bu kadar kolay sarlabilir mi?

Belde - Biraz zaman lazım bunun için, belki de bu kadar kolay değil.

Zozan - Mesela barış anaları var. İki çocuğunu gerilla olarak kaybetmiş, bir çocuğunu asker şehit olarak kaybetmiş. Onlar hala barış diyorlar mesela. Ben onlar kadar olabilir miydim, kestiremiyorum açıkçası. Çok çabuk affedebilir miydim bu kadar bilemiyorum. Onların bu duruşuna saygı mı duymak lazım, yoksa bir taraftan başka mı düşünüyorlar bizden daha başka mı düşünüyorlar bilemiyorum...

Belde - Belki de daha insani bir yerden, doğru bir yerden...

Zozan - Çok içleri yanmış artık, bunu unutmaya hazırlar. Bunu hiç kimsenin yaşamasını istememe duygusu olabilir. Bilemiyorum. Ama o söylediğin, bu iki taraflı şiddet... Bir kere TSK ile bir gerilla hareketi aynı değil. Çünkü biz silahlı kuvvetleri her yerde görüyoruz. Ama burada gerilla sokakta, bizim yolumuzu keserek, kimliğimizi falan sormuyor, bizim evimizi basmıyor. Ama hani TSK’nin sokak tacizi... Yarın mesela eylem var, geçen gün yine güvenlik şube aradı, bir sürü sorular sordu, yani bunu mesela yapmıyor gerilla. Bu aynı şey değil yani. Ama bir de askere gidenler için, oraya gelecektim, mesela askerlik meselesi aslında ciddi bir şekilde bu cinsiyetçiliği, erkeklere ciddi bir şekilde aşıllyor. Orada kadınlar aşağılanıyor, "kadın gibi ağlama" deniyor, oradaki verilen hareketleri yapamayanlara, "kadın, ibne" falan diye dalga geçiliyor. Orada tamamen heteronormatif bir şey var. Bir de en sertinden. O çok aslında erkekliği pekiştiriyor, yani askerlik. Bizim günlük hayatımıza da çok yansıyor. Savaşan biri de aynı şekilde. Savaşan birinin kadın askerlere tecavüz edipte buralarda aramızda dolaşanları var. Beni birazcık bu taraflar korkutuyor. Nasıl onlar normal hayata dönebilirler.

Aynı şeyi gerilla için de söyleyebilir misiniz?

Zozan - Aynı şeyi gerilla için duymadım. Mesela, kadın Türk asker ya da erkek askerlere tecavüz edip, bedenlerine zarar verdiklerine dair bir şey duymadım. Henüz böyle bir şey yok. Ama karşılıklı bir savaş var sonuçta.

Belde - Ama savaş bir kirlilik halidir. Sen orda çok temiz bir şey olarak durmuyor. Karşındaki ne kadar kirliyse, sana da bulaşıyor o kir.

Zozan - Sadece eşitleyemiyorum. İkisinde de var ama sadece eşit durumda değiller.

Peki bu şiddet toplumun belleğinden nasıl silinecek?

Belde - Silinmekten önce yüzleşme olmalı, o yüzleşmede iki tarafın ve insanların, herkesin çok açık kalplilikle ve vicdanla davranmaları ve hissetmeleri gerekiyor ki... Yani ilk başta silinmez ama ilk önce herhalde bir anlaştıklarını hissedecekler. O durumlarının, o mağduriyetlerinin, yaşadıkları acıların anlaşıldığını hissedecekler. Belki böyle, ilk başta rahatlayacaklar, sonra yavaş yavaş belki silinecek.

Peki somut olarak ne yapılabilir?

Zozan - Hakikat komisyonları kurulmalı

Belde - Bir de kayıplar var. Kayıplar hala bulunmuyor, onların hesabı verilmiyor, birtakım böyle hikâyeler... O hikâyeleri kimse bilmiyor. Çocuklar ölüyor, mesela Uğur Kaymaz. Uğur Kaymaz'1 vuran insanlar neredeler? Bu insanlar yoklar. Onlar bile bulunmuyor, cezalandırılmıyor. Yani bu toprakların onlara adil davranmayacağını, işte bu hükümetin onlara adilce yaklaşmadığını hissediyorlar. Sonra bir de Türkiye'nin batısının bunu görmediğini hissediyorlar. Yani benim bir acım var, bana çok büyük bir yerden haksızlık yapılıyor ve bunu kimse görmüyor. Bununla ilgili kimse ses çıkarmıyor. Gezi zamanında da o sitemler hep böyleydi. Yani "biz burada bu kadar öldük kimse birşey yapmadı, bir ağaç için herkes cinnet geçirdi” falan diye sitemleri vardı. Bu sitem anlaşılır bir şey. Önce görmek, anlamak, tabii ki bir de adaletin yerini bulması... Geç de olsa o insanların acısının görülmesi, acı çektirenlerin cezalandırılması gerek... Zaten normal bir cezalandırma süreci bile işlemiyor. 
Yani önce bir yüzleşme, sonra da bir cezalandırma sürecinden söz ediyorsunuz?

Belde - Yüzleşmeye karar verilirse yani o cezalandırma sistemi de işler, işletilir.

Bir hakikat komisyonundan söz ettiniz, bunu biraz açar mısınız?

Zozan - Devlet nezdinde bir şeyden sözediyorum. Hatta en son da Taraf Gazetesi'nde falan da baya yer aldı. Gidip birebir köyleri yakan kişiler vardı, mesela Mardin'de. Devlet de hatta ceza aldı bu konuda. Mesela bu biraz iyi geldi bana. Devlet bir kaç bin euroluk tazminat ödemek zorunda kaldı AİHM'e. Ama bu mesela çok gecikmiş bir şey.

Belde - Ama bunlar da Türkiye'nin kendi iradesiyle yaptığı şeyler değil. AİHM mesela, AİHM'den çıkıyor, Türkiye'nin kendi içinde çıkmıyor. Böyle bir cesareti yok. Birilerinin zorlamasıyla işte hani kendi şeyleriyle yapmiyorlar. Ayak diriyorlar hatta.

Barış sürecininde mi öyle olduğunu düşünüyorsunuz?

Belde - Şu anda öyle değil mi, ben öyle düşünüyorum. Şu anda da ayak diriyorlar

Şu anda Türkiye'de süregiden barlş sürecinide mi dış konjonktürün belirlediği bir süreç olarak görüyorsunuz?

Belde - Dış konjonktürün bir etkisi var bence. Artık bu iş gitmiyor. Bu coğrafi koşullarla da dünyanın bu haliyle de bu iş artık yürümüyor. Bu yüzden de Türkiye'de güçlü devlet olacak işte falan filan... Bölgede güçlü olacak ya. Kürt sorununun devletin ayağına takıldığını düşünüyorum ben. Bu yüzden de çözmek istiyor, yoksa çok sevdiğinden değil. Zaten çok sevdiğinden olsa, büyük bir adaletsizlik olduğunu düşündüğünden olsa, doğru düzgün şeyler yapar, doğru düzgün, daha sistemli adımlar atar. Zoraki yaptığını düşünüyorum.

Zozan - Bu konu her yerde, her zaman Türkiye'yi zor durumda birakan bir şey Kürt meselesi. Mesela CEDAW'da da gördük. CEDAW'da şöyle bir şey olmuştu: Biz oraya 20 kadın falan gittik. 2005 yılında Gölge Raporu hazırladık. Sonra bizde başka bir rapor hazırladık Kürt kadınları. Çünkü CEDAW raporunda çoğu konu yoktu. O bir konsensüs metni olduğu için biz de ayrı bir metin hazırladık. Başörtülüler de başka bir metin hazırladılar. Mesela biz orada bazı kişiler tarafından çok dışlandık. Hatta Türkiye’ye Kürt meselesiyle ilgili çok ciddi sorular geldi. Türkiye zor durumda kaldı. Bazı kadınlar "Eyvah! Türkiye ne kadar kötü durumda kaldı diye üzüldü mesela. Biz de sevindik. Oraya hepimiz kadın paydasında gitmiştik ama böyle bizi yeren iki mesele vardı orada. Hatta TCK'deki bazı maddelerden çok Kürt meselesi ile ilgiliydi sorulan sorular; anadilde eğitim falan bunları sordular. O soruların aslında bütün kadınları kapsayan diğer soruları daha gölgede bıraktığını düşünen kadınlar da vardı. Bunları çözelim de diğer sorunlar da çözülür gibi bir bakış açıları vardı. Orada mesela biz başörtülü arkadaşlarla bir dönem yalnız kaldık zaten, dışlanmış kişi olarak. İlginç bir deneyimdi aslında benim için.

Öyleyse kadınların ortak bir barış tanımı yok diyebilir miyiz?

Zozan - Tabii ki yok, tabii ki. Hala eskiden başörtülü ya da Kürt-Türk yoktu deniliyor. Nasıl yoktu yani? Biz görünmüyorduk, biz bağıramıyorduk, biz söyleyemiyorduk. O yüzden yoktuk.

Belde - Aksu (Bora) şey dedi ya, avantajlı olan avantajını fark etmez. Yani fark etmiyor. Köşedeki itilmiş hissediyor tabii ki, ağırlığını tamamen hissediyor. Ama biri diyor ki ya yoktu ki böyle bir şey falan. Ya elbette yoktu, yani senin için yoktu. Sen rahat, huzurlu beyaz beyaz takılıyordun tabii!

Bu da aslında kadın hareketini de ayrıştırıyor kendi içerisinde ve en temel anti-militarist tutumda barış konusunda bile ortak bir iradenin gelişmesine engel oluyor?

Belde - Belki şu anlarda biraz daha iyidir eskiye göre. Ne bileyim beş- on sene öncesine göre. Çünkü sonuçta biz bir sempozyum yaptık herkes geldi, dindar kadınlar, feminist kadınlar falan değil mi? Hepsini toparlayabildiğimize göre demek ki o kadar da, eskisi gibi sert değil?... Mesela Barış İçin Kadınlar Platformu var. Mesela böyle bir takım önemli platformların içinde herkes var. Herkesin etkisi var. Oralarda biraz ortak diller üretilmeye, kurulmaya çalışılıyor, son bir iki- üç yılda.

Peki, bu konuya annelerle başlamıştık. Zozan, ben olsam, çocuğumu kaybetmiş olsam bu kadar kolay barışamayabilirdim demişti. Tekrar o konuya dönelim, barışın annelik üzerinden kurulmasına nasıl bakıyorsunuz? 
Zozan - Bu tam toplumsal cinsiyet rollerini pekiştiren bir şey.

Belde - Yani anneliğe yüklenen kutsallığa biraz daha kutsallık katan bir şey oluyor.

Zozan - Evet, evet... Mesela şehit anneleri de aynı düzlemde değiller mesela. Bir daha olsa yine yollarım diyor. Çok farklı yani... Onlar bu barış sürecinin içine çekilmemiş kişiler. Onlar daha bunu idrak edememiş kişiler. Onlar daha sertler yani. Ben öldüm, başkası ölmesin diyen de vardır mutlaka. Hatta Başbakan’ı da çok rahatsız eden bir anne vardı ya... Hepsi öyle değil keşke o kadın gibiler daha çok ses çıkarsa. Ama olmuyor işte. Şöyle bir şey de var, biz Barış Meclisi olarak, 84 örgüt barış anası bir kadınla, bir şehit ailesini yan yana getirdik. Bence çok iyi bir şeydi bu. İkisi de ortak şeyler söylediler. Çok da böyle siyasi değillerdi. Şehit babası mesela çok mantıklı konuştu. Verdiği mesaj çok barışa dönüktü, çok insaniydi. Aynı şekilde barış anasının da öyle bir söylemi vardı, o da çok iyiydi. Mesela sonradan şehit ailesi devlet tarafından bir tepki almış. Hani böyle bir yüzü de var meselenin. Aslında onlar şehit ailesi olarak devletin birtakım imkânlarından faydalanıyorlar. Ondan dolayı biraz ona göre şekilleniyorlar, onların duruşları da ona göre şekilleniyor. O çok sorunlu işte bir taraftan.

Şiddetin bu toplumdaki çıktılarından sözettik. Kadınlar açısından baktı̆̆ımızda, şiddetin kadınların hafızasında nasil bir yeri olduğunu söyleyebilirsiniz?

Belde - Çok travmatik bir yeri olabilir, başka nasıl bir yeri olabilir ki...

Bu travma aktarllyyor mu, paylaşıllyor mu?

Zozan - Yok öyle bir şey. Yani güvenmemeyle ilgili bu bence. Mesela jandarmaya gitmez kadın. Çünkü büyük düşmanla bir durum var orada. Erkek bir devlet var. O, kadını da dövüyor, kocasını da dövüyor, çocuğunu da dövüyor. Ondan şiddet geliyor. Aile içerisinde olursa büyük düşmana karşı bir suskunluk var. Bu durum mesela, kadınları çok susturan bir șey bu coğrafyada. Hatta son dönemde Aile ve Sosyal Politikalar Bakanlığı'nın bir araştırması olmuştu. Doğu ve Güneydoğu'da şiddet daha az diye. Aslında kadınlar çok başvurmuyor, ondan dolayı az görünüyor. Karakola gitmiyor, jandarmaya gitmiyor. Devleti temsil eden kurumlara gitmeyi tercih etmiyor. Şikayet etmek istemiyor. 2009'dan beri bu çok azaldı. Çünkü KCK'den dolayı cezaevinde olan çok insan var. Şiddet de görse gitmiyor kadın, çünkü ya kocası cezaevinde ya çocuğu ya komşusu ya akrabası... Bu çok ciddi bir engeldir yani.

Kadına yönelik şiddet perdenin gerisinde kalıyor yani. Şimdilik bunları bir geride tutayım diyor kadınlar. Öyle mi?

Zozan - Kesinlikle, sonuçta içinden daha çok çıkılamayacak bir hale gelir eğer şikayet ederse, eve polis gelirse, adama başka bir şey yapan olursa...Öyle bakıyor kadın... Doğal olarak öyle bakıyor...

Bu bahsettiğiniz daha çok aile içi şiddete yönelik bir şey. Peki devlet şiddeti kadınların hafızasında nasıl yer ediyor? Buna ilişkin bir aktarım var mi?

Zozan - Hayır çok zor o. Mesela tecavüzler... Kürt coğrafyasında köydeki kadınlara şöyle şeyler yapılıyor. Mesela korucu eviyse falan, jandarma sürekli gidiyor, kadın yalnızken de gidiyor. Bu bir köy ortamında korkunç bir şey demek.

Kadının itiraz edebilme hakkı da yok, değil mi?

Zozan - Yok tabi ki... Hiçbir yerde göremezsin sen "ben cezaevinde tecavüze uğradım” açık açık diyen, haykıran bir kadın grubu yok tabi. Bu daha namus meselesi gibi görülüyor.

Belde - Kürt bir kadının tecavüze uğraması, daha çok etnik bir şey olarak görülüyor... Savaş tecavüzünün öyle bir anlamı vardır ya zaten birazcık.

Zozan - Bunu dışarıya böyle yansıtmak istemezler, yansıtmazlar yani.

Bu nasıl çözülüyor? Kadın o travmayla yalnı mı başediyor? Mesela ailesi biliyor mu? Biliyor da bilmemezlikten mi geliyor?

Zozan - Herkes biliyor da bilmezden geliyor daha çok.

Belde - Şöyle bir şey anlattı Urfa'daki çalıştayda, ordaki bir kadın. O da işte PKK'nın ve bu hareketin devrimciliğine dikkat çekti ve şey dedi. Köyde bir kadına, korucu tecavüz etmiş. Tabi köyde kimse evlenmiyor 
onunla Köydeki politik bir genç demiş ki ben onunla evleneceğim. Çünkü onlar ona acı çektirdi biz niye acı çektiriyoruz ona falan diye evlenmiş onunla.

Tecavüz sonrasl çocuk oluyor mu? O zaman ne oluyor?

Zozan - İşte onlar daha çok çıkıyorlar basına falan, N.Ç., Ş.E. gibi... Mesela Eren Keskin'in bir çalışması vardı. Orada da kadınların hep baş harfleri vardı. Kadınların hiçbiri adıyla "ben böyle bir şey yaşadım ve bunun mücadelesini vereceğim” demek çok çok zor yani. Bu çok gizli kalıyor. Davaya yansımış olanları herkes öğreniyor tabi.

Son iki sorumu sorayım size. Sizce feminist çalışmaların, yani bu savaş-soykırım-hafıza üzerine yapılan çalışmaların, kadınlarda bilinç yükseltmesine bir etkisi oldu mu?

Zozan - Ben mesela anti-militarist feminist Cynthia Enloe'yi okuduktan sonra ufkum çok açıldı. Aslında dünyadaki feminist kadınların çalışmaları biraz daha Türkiye'dekileri etkiledi. Türkiye'de de mesela her zaman onlara atıfta bulunuyorlar. Her anti-militarist bir şeyde mutlaka onlara atıf yapan bir söylem görüyorum. Mesela zaten Türkiye'de bu konuda çalışan akademisyenler de daha çok yine onların kitaplarını falan çevirdi. Mesela makalelerin olduğu bir kitap okumuştum Vatan- Millet-Kadınlar (Ayşegül Altınay). Çok çok iyi makalelerin olduğu bir derlemeydi mesela. Biraz yurt dışı terminolojisi, ama tabi feminist kadınların söylemleri, antmilitarist, vicdani retçi kadınların söylemleri, askerliğe karşı çıkışları falan bu topraklarda çok önemli.

Belde - Hem feministlerin hem de gerçekten anti- militaristlerin ve anarşistlerin katkıları da var. Mesela Van'da dergi tayfasının, Qijikareş'in etkisi önemlidir. Abdullah Öcalan’ı da, PKK hareketini de eleştirirler. Sadece tahammül yaratma açısından bile, daha demokratik bir ortam sağlamak açısından bile yaptıklarının önemli olduğunu düşünüyorum.

Son olarak size şunu sorayım. Barış sürecinde kadınların yeterince yer aldığını düşünüyor musunuz?

Zozan - Hayır. Barış Meclisi’nde bile tek kadın örgütü biz varız.

Ciddi mi söylüyorsunuz?

Belde -Tabi varlıkları vardır da belki ama politik ve zihinsel olarak katkıları yok.

Zozan - Etkinliklere katılıyorlar, ama hani tartışma süreçlerine katılmıyorlar.

Son olarak eklemek istediğiniz bir şey var mı?

Zozan - Barış için şu anda Türkiye'deki genel eğilim: Kürtleri ehlileştirmek. Ama ben öyle bir yöntemin olmaması gerektiğini düşünüyorum. Bu yanlış bir şey. Kürtleri ehlileştirelim entegre edelim bu topluma. Biraz haklarını verelim ve entegre edelim. Budur yani şu anki proje.

Seni böyle düşünmeye iten şey Demokratikleşme Paketi mi?

Zozan - Evet çünkü fiiliyatta hiçbir şey yok...Korkunç bir şeydi. Ne vardı ki içinde hiçbir şey yoktu. Biraz bir şey veriyor gıdım gıdım. Bizlere şey veriliyor paket paket hak veriliyor. Böyle bir şey olamaz ki. Bir de ben şöyle düşünüyorum. Sen kimsin bize hakkımızı vereceksin? Hepimiz de bekliyoruz. Ben o süreçlerde, kaçıncı paket açıklandı, her seferinde bir Kürt olarak çok üzüldüm. Mesela gündemde olmayan hasta tutsaklar var. Madem savaş bitti şu anda, hani cezaevleri de eğer cephelerin bir parçasıysa, hani sürgün ve tutsaklık alanlarıysa niye...

Belde - Hasta tutsakların zaten kanunen çıkmaları gerekiyor.

Zozan - Ona uyacaklar yani. Ama onu çıkartmıyorlar. Bence bu en somut yapılması gereken şey, bunu yapmıyorlar. Sürgünde bir dolu Kürt var onlar için hiçbir şey yapmıyorlar. 